\title{
Arquitectura tradicional indígena del occidente de Panamá
}

\section{Miguel Ángel Hervás Herrera ${ }^{\mathrm{a}}$ y Jonathan González Quiel ${ }^{\mathrm{a}}$}

${ }^{a}$ SENACYT, Panamá, mangelhervas@yahoo.es, jonathangonzalezquiel@gmail.com

\section{Resumen}

Se presentan los resultados de un proyecto de investigación sobre la arquitectura vernácula de las comunidades indígenas del occidente de Panamá. El ámbito de estudio se centra en los territorios indigenas de las etnias Ngäbe, Buglé, Naso y Bribri. Todas ellas pertenecen a un área geográfica bien definida, y están unidas por estrechos vínculos históricos, sociales y culturales.

Las páginas que siguen tratan sobre la morfología, la estructura, los materiales, las técnicas constructivas, la tipología y la función de las construcciones objeto de estudio, levantadas con materias vegetales del entorno inmediato.

Palabras clave: Panamá, arquitectura tradicional, comunidades indígenas, Ngäbe, Buglé, Naso, Bribri.

\begin{abstract}
The results of a research project on the vernacular architecture of indigenous communities in western Panama are presented. The field of study focuses on the indigenous territories of the Ngäbe, Buglé, Naso and Bribri ethnic groups. All of them belong to a well-defined geographical area and are linked by close historical, social and cultural ties.

The following pages deal with the morphology, structure, materials, construction techniques, typology and function of the buildings under study, built with plant materials from the immediate environment.
\end{abstract}

Keywords: Panama, vernacular architecture, indigenous communities, Ngäbe, Buglé, Naso, Bribri. 


\section{Introducción}

En el extremo occidental de la República de Panamá, junto a la frontera con Costa Rica, habitan cuatro pueblos indígenas (Ngäbe, Buglé, Naso y Bribri) que mantienen aún en buena parte sus modos de vida tradicionales, también en lo que se refiere a arquitectura. Sus construcciones tradicionales se basan en el uso de materias vegetales del entorno inmediato, cuentan con un enorme valor cultural, medioambiental y estético, y reflejan de una forma muy precisa la manera de vivir de las gentes que las levantan y utilizan. Identificada con su entorno natural y dotada de altos niveles de eficiencia medioambiental y sostenibilidad, esta arquitectura contribuye de un modo muy significativo a la definición de la identidad de estos pueblos, y actúa como vehículo de expresión de los mismos y como reflejo de su adaptación al medio. De hecho, son los propios indígenas quienes mayor importancia conceden a los valores identitario y medioambiental de su arquitectura tradicional. Sin embargo, es un patrimonio poco conocido y escasamente valorado fuera del ámbito indígena, y vulnerable ante las numerosas agresiones que comprometen su conservación, debido en su mayor parte a la introducción de los nuevos materiales industriales.

Además, el conocimiento de esta arquitectura puede aportar datos muy valiosos para la interpretación de los restos materiales del pasado panameño, y servir de ayuda a la interpretación de determinadas estructuras identificadas en yacimientos arqueológicos del país. Es el caso del sitio de El Caño, cementerio de élite fechado por radiocarbono entre los siglos VIII y XI d.C., donde las últimas excavaciones arqueológicas han sacado a la luz un amplio conjunto de huellas de poste en el área ceremonial, correspondientes a edificios de madera desaparecidos, y cuya interpretación se ve dificultada por la ausencia de estudios científicos sobre paralelos etnográficos próximos (Hervás, 2018).

Dadas estas circunstancias, resulta del máximo interés abordar el estudio científico de esta arquitectura, no sólo con el objetivo de salvaguardar su indudable valor documental para la historia del país y de sus modos de vida, sino también, y sobre todo, para sentar las bases de su adecuada valoración, protección y salvaguarda. Con este objetivo, la Secretaría Nacional de Ciencia, Tecnología e Innovación de Panamá (SENACYT) financia un proyecto de investigación titulado "Arquitectura tradicional de las comunidades Indígenas del Occidente de Panamá", que comenzó su andadura a principios de 2019. El proyecto está gestionado desde la Fundación para el Desarrollo Integral Comunitario y Conservación de los Ecosistemas de Panamá (FUNDICCEP), y está siendo llevado a cabo por un equipo multidisciplinar de investigadores integrado por arqueólogos, geógrafos, arquitectos, botánicos y antropólogos.

La zona de estudio seleccionada se ubica en el oeste de Panamá, dentro de la Comarca Ngäbe-Buglé y de la provincia de Bocas del Toro. En concreto, en las comunidades de: Piedra Grande (territorio Buglé, corregimiento de Agua Salud, distrito de Ñurum, comarca Ngabe Buglé); Filo Verde (territorio Ngäbe, corregimiento de Tu Gway, distrito de Jirondai, comarca Ngabe Buglé); Guabo de Yorkin y Dacle (territorio Bribri, corregimiento de Las Delicias, distrito de Changuinola, provincia de Bocas del Toro); y Sieiyic, Sieikin y San San Dru Di (territorio Naso, corregimiento del Teribe, distrito de Changuinola, provincia de Bocas del Toro) (Fig. 1). Forman un conjunto coherente por su pertenencia a un área geográfica bien definida con vínculos históricos, sociales y culturales estrechos entre ellas.

La investigación en curso está orientada a conocer la morfología, estructura, materiales, técnicas constructivas, tipología y función de los edificios producidos con técnicas tradicionales propias por las comunidades indígenas seleccionadas. Se pretende conocer los procedimientos intervinientes en la producción de esta arquitectura (mecanismos de obtención, transporte y puesta en obra de las materias primas, sistemas de contratación de personal o de colaboración de la comunidad, jerarquización y grado de especialización del personal participante en las obras de construcción, financiación, costes, propiedad, procedimiento administrativo...), y contribuir a su conservación y puesta en valor a partir de la adecuada valoración social de estos edificios y del saber tradicional del que emanan.

\section{Metodología}

Estamos elaborando un catálogo de los edificios más representativos de la arquitectura tradicional de las comunidades indígenas seleccionadas, compuesto por una base de datos con fichas catalográficas de cada uno de ellos, y por los correspondientes archivos fotográfico y planimétrico, más un estudio publicable que permita la contextualización geográfica e histórica del conjunto de edificios estudiado, la clasificación morfotipológica y funcional de los mismos, la 
valoración de su estado de conservación y medidas correctoras a aplicar, y la identificación de las peculiaridades de la arquitectura tradicional de cada comunidad. Para ello se están manejando de manera simultánea cuatro registros:

- un registro descriptivo basado en un modelo de ficha de inventario informatizable caracterizada por su versatilidad y estructuración, y por la capacidad de contener información gráfica;

- un registro fotográfico basado en la aproximación secuencial al edificio, consistente en la toma de imágenes en tres escalas de trabajo o niveles de detalle distintos: escala entorno, escala edificio y escala detalle;

- un registro planimétrico a base de croquis de planta, sección y alzado de los edifícios, completado con la obtención de modelos digitales tridimensionales de los ejemplares más representativos de cada una de las tipologías identificadas;

- encuestas orales realizadas sobre el terreno a personas previamente seleccionadas por sus conocimientos sobre el proceso de construcción de los edificios, que actúan como fuente de información primaria.

Los edificios están siendo estudiados en su contexto geográfico y antrópico más preciso, y se está indagando en los vínculos existentes entre función, forma y soluciones estructurales. Se buscan respuestas a los principales interrogantes (quién, cómo, porqué, para qué) planteados por los diversos aspectos del proceso constructivo (materiales, técnicas constructivas, soluciones formales y estructurales, funcionalidad, eficiencia, valor simbólico...). Asimismo, se valora el estado de conservación de los edificios estudiados, los riesgos a los que se enfrentan, y las posibles soluciones a adoptar al respecto en distintos niveles (normativo, educativo, de difusión...).

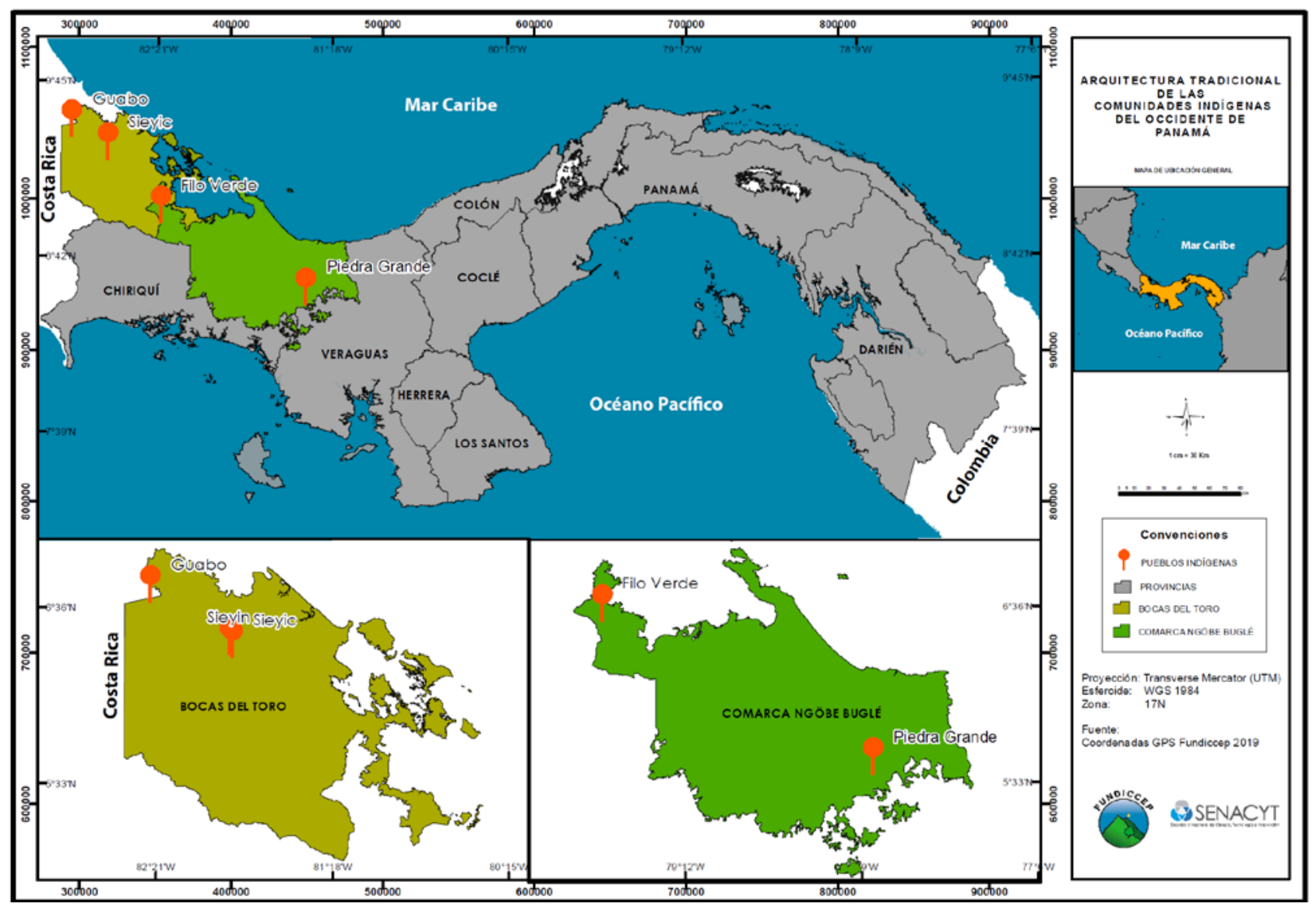

Elaboración: Ingrid Cárdenas Rodríguez

Fig. 1 Mapa de localización de las comunidades objeto de estudio 


\section{El área de estudio}

La investigación se centra en los territorios indígenas de los cuatro grupos étnicos presentes en el extremo oeste del país: Bribri y Naso en la provincia de Bocas del Toro, y Ngäbe y Buglé dentro de su propia comarca. Se trata de pueblos de origen prehispánico, de raíz lingüística chibcha. Estas cuatro etnias pertenecen a un área geográfica bien definida, y presentan entre sí estrechos vínculos históricos y sociales, pero también características culturales propias muy marcadas. Además, habitan dos medios físicos muy diferentes (bosque tropical húmedo y sabana en zonas de montaña), por lo que configuran un ámbito de estudio muy interesante, en el que poder observar semejanzas y diferencias, y valorar el grado de influencia del medio físico y del entorno cultural en las distintas variantes que ofrecen las manifestaciones arquitectónicas de cada grupo.

El medio físico resulta determinante en la definición de la arquitectura tradicional de estos grupos, en especial el clima, porque impone unas condiciones de temperatura, insolación y humedad que condicionan directamente la habitabilidad de los espacios (Díaz, 2018). Además, es el medio físico el que proporciona las materias primas para la construcción, que en este caso son de origen casi exclusivamente vegetal, y como es conocido, la vegetación está fuertemente condicionada por el clima. En las comunidades estudiadas, además, las posibilidades de transporte de materias primas son especialmente limitadas, porque el bosque tropical húmedo combinado con el paisaje de montaña de la Cordillera Central de Panamá determina que muchas de estas comunidades no sean accesibles con vehículos, sino únicamente a pie o a lomos de bestias de carga.

Las comunidades Ngäbe, Naso y Bribri incluidas en el estudio se asientan en zona de bosque tropical húmedo o muy húmedo, en la que llueve durante casi todo el año, se dan temperaturas promedio elevadas, y altos índices de humedad ambiental, lo que determina que sea necesario elevar las construcciones para evitar la humedad del terreno, disponer de cerramientos permeables que permitan la circulación del aire para eliminar la humedad ambiente por convección, y cubiertas vegetales muy densas y de fuerte inclinación, que actúen como regulador térmico de los espacios interiores frente a la insolación, y que resistan los muy caudalosos aguaceros de la zona. El medio físico proporciona una amplia variedad de palmas, arbustos, bejucos y maderas para utilizar en la construcción, como veremos.

Las comunidades Buglé, en cambio, ocupan una zona de sabana en montaña, con clima tropical, pero con índices pluviométricos muy variables a lo largo del año, temperaturas nocturnas más bajas que las del bosque tropical, elevada exposición a los vientos, y una cobertera vegetal muy exigua. Hay menos humedad en el suelo, y es necesario protegerse de los fuertes vientos, por lo que se prefieren cerramientos perimetrales impermeables a las corrientes de aire. La disponibilidad de materias vegetales es más limitada, especialmente en cuanto a variedad y porte.

Por lo que respecta al entorno cultural, los cuatro grupos indígenas presentes en el área de estudio parecen tener su origen en poblaciones de raíz histórica chibcha establecidas en la zona desde época precolombina (Marín, 2004, p. 4, nota 19). Con unos 154000 miembros censados, el pueblo Ngäbe constituye el grupo indígena más importante dentro del área de estudio, y el de mayor tamaño de Panamá. Conjuntamente con los Buglé, disponen de una extensa comarca propia enclavada entre las provincias de Bocas del Toro, Chiriquí y Veraguas, en las que también tienen una presencia importante. La organización social de los Ngäbe y los Buglé se basa en una estrecha relación entre el usufructo de la tierra y el parentesco, y las poblaciones o comunidades de estas etnias agrupan núcleos familiares emparentados y vinculados entre sí por relaciones de trabajo, lo que proporciona a cada comunidad una fuerte solidez interna. Los Bribri ocupan un extenso territorio a ambos lados de la frontera entre Panamá y Costa Rica, por lo que tienen estatus jurídico de grupo transfronterizo, si bien el pueblo Bribri panameño se encuentra confinado en una zona bien delimitada junto a las riberas de los ríos Yorkin y Sixaola, en el distrito de Changuinola de la provincia de Bocas del Toro. En este mismo distrito se asientan los Naso, que constituyen un grupo minoritario concentrado en un área reducida a orillas de los ríos Teribe y San San. Su tradición cultural es muy próxima a la de los Bribri, pues se encuentran estrechamente emparentados con los Talamancas de Costa Rica, y recibieron fuertes influencias de los Misquitos a lo largo de los siglos XVIII y XIX (Davis, 2010, pp. 28-30). 


\section{Construcción tradicional indígena en Panamá}

\subsection{La estructura del núcleo habitado}

Los estrechos vínculos históricos, sociales y culturales que estas cuatro etnias mantienen entre sí determinan la existencia de un importante número de paralelismos y coincidencias entre sus respectivas formas de habitar y construir. El poblamiento se distribuye en pequeños núcleos habitados muy dispersos llamados comunidades, con frecuencia próximos a ríos caudalosos, y situados casi siempre en zonas de muy difícil acceso. La mayoría de estos núcleos carece de una estructura propiamente urbana. En áreas de bosque tropical, las viviendas ngäbe, naso y bribri simplemente ocupan un claro en el bosque, creado por los propios moradores de la misma al cultivar el terreno circundante, y están separadas de las viviendas vecinas por distancias que a veces superan el centenar de metros, en trechos ocupados por bosque tropical virgen. Lo mismo sucede en el caso de las comunidades buglé presentes en zonas de sabana de montaña, constituidas por viviendas dispersas en un entorno de escasa vegetación. En este ámbito cultural se ha observado una mayor tendencia a la centralización del núcleo habitado, probablemente debido a la ausencia de una cobertera vegetal tan densa como la del bosque tropical, circunstancia que parece facilitar la agrupación vecinal, aunque sin que llegue a constituirse por ello una estructura propiamente urbana. Tampoco existen infraestructuras de servicio tales como redes de saneamiento, o de distribución de agua potable o de electricidad. Cada familia dispone de un retrete conectado con un pozo ciego, y situado dentro del predio familiar, pero a varias decenas de metros de distancia del área habitacional.

En muchas de estas poblaciones, una parte del núcleo se encuentra organizada en torno a una gran plaza comunal que sirve de cancha para jugar al fútbol o celebrar festividades o actos de concurrencia pública, alrededor de la cual se distribuyen edificios comunales, como la escuela, la iglesia, la sala de juntas para celebración de asambleas comunitarias, la sala de justicia comunal, o el consultorio médico. No obstante, esta solución no forma parte de la tradición cultural indígena, sino que es el resultado de una política promovida por el Estado panameño durante el gobierno del General Omar Torrijos (1968-1981) para dotar de una estructura homogénea a las comunidades.

Por otra parte, en estos núcleos se observa un cierto margen de movilidad interna, pues, bajo determinadas circunstancias - como el agotamiento de los terrenos de cultivo del entorno inmediato-, las familias pueden desmontar sus casas y volverlas a montar a unos centenares de metros de distancia, dentro de la misma comunidad.

\subsection{Materias primas para la construcción. Obtención y trasporte}

Se trata de una arquitectura casi exclusivamente vegetal, realizada a base de maderas y plantas herbáceas, mediante el empleo de especies del entorno inmediato. Los elementos estructurales se elaboran a partir de troncos o ramas de árbol de diferentes especies, elegidas de entre las disponibles en el entorno próximo en función de sus propiedades físicas y de los requerimientos estructurales de cada pieza. Así, en los grupos étnicos establecidos en áreas de bosque tropical, los pies derechos destinados a soportar el peso de toda la estructura a compresión, cuya base ha de estar empotrada directamente en el subsuelo, en contacto directo con muy elevados índices de humedad capilar, se fabrican a partir de maderas muy poco porosas y muy duras, como el palo criollo (Minguartia guianensis), el arraiján (Eugenia ligustrina) o el mangle (Rizophora mangle L. y Pelliciera rizophorae). Para las jácenas, jabalcones, pares de cubierta, cabrios, etc, se prefieren maderas más ligeras y flexibles, pero con buenas propiedades mecánicas, como el laurel (Cordial alliadora). Los cerramientos perimetrales y los revestimientos de los forjados se construyen con tabla de cedro espino (Bombacopsis quinata), que es una madera ligera con peor comportamiento estructural que el laurel. Para los elementos auxiliares como barandillas, parapetos, tabiques, etc., se usan troncos y cortezas de diferentes tipos de palma - chonta (Triartea gigantea), jira (Socratea durissima), pifá (Bactris gasipaes)...-, que aportan maderas muy blandas y fáciles de conseguir y de trabajar (Ocampo, 1994, pp. 16-21). Para los atados entre elementos, tradicionalmente se han usado bejucos (tallos largos, delgados y resistentes que cuelgan de determinadas especies de árboles tropicales), aunque en tiempos recientes se recurre frecuentemente al uso de hilo de nylon de producción industrial. En ocasiones, la estructura de cubierta se monta a base de piezas de bambú, material muy ligero, flexible y extremadamente resistente que, no obstante, se reserva con mucha más frecuencia para la construcción de cercados. 
El elemento que presenta una mayor variedad entre los grupos étnicos objeto de estudio es el cobijo vegetal de la cubierta. Así, mientras los bribri cubren sus edificios con las hojas de una planta herbácea llamada suita (Asterogyne martiana), los naso lo hacen con hojas de palanquilla (Geonoma congesta), los ngäbe con hoja de palma conga (Welfia georgii), y los buglé con la denominada paja hueso (Trachypogon plumosus), omnipresente en la sabana de su entorno (Ocampo, 1994, pp. 16-21).

El proyecto de investigación en curso ha permitido documentar también los procesos de extracción de estas materias primas. En el bosque tropical, los puntos de extracción se localizan en las inmediaciones de los núcleos habitados, o junto a las márgenes de los ríos, que sirven como vía para el transporte. El despiece de los troncos para obtención de vigas o tablas se hace habitualmente en el propio punto de extracción, dado que suelen localizarse en lugares inaccesibles para vehículos. Tradicionalmente, los trabajos de despiece se hacían con hacha, cuñas y mazos, y con sierras largas de dos empuñaduras. En la actualidad, se lleva a cabo con motosierra, cuyo uso se generalizó en la zona para estas tareas a partir de la década de 1990. El despiece de la madera es el único trabajo realmente especializado que se hace en este tipo de construcción: las restantes actividades del proceso constructivo son realizadas por las propias familias.

El transporte de vigas, tablas, o fardos herbáceos u hojas de palma desde los puntos de extracción hasta el lugar de construcción se hace casi siempre a pie, a veces con la ayuda de caballerías, o a lo sumo, aprovechando las corrientes fluviales y la flotabilidad natural de la madera. A este respecto, es preciso recordar que la mayor parte de las comunidades son innacesibles para vehículos de motor.

\subsection{Tipología de edificaciones}

El tipo más antiguo documentado de edificación en el área de estudio es una construcción de planta circular y desarrollo cónico en altura, en la que la estructura de cubierta apoya directamente sobre el terreno, sin paredes verticales (Fig. 2). Este primer modelo está estrechamente relacionado con la cosmovisión, con el mundo de creencias ancestrales de los grupos indígenas estudiados (González y González, 1989). Entre los ngäbe y los buglé, la casa redonda, de una sola pieza, un solo fogón y una sola alacena, está relacionada con el concepto de casa común, la primera construida en la historia, estrechamente vinculada con la naturaleza (Quintero, 2017). Entre los bribri, este primer modelo cónico, denominado Ú-Shure, tiene su correspondencia en la Casa Cósmica, y era la imagen de la casa construida por Sibö, metáfora del mundo habitado por el ser humano, un microcosmos reflejo del macrocosmos (Guevara, s/d: 22-23).

Con el tiempo, este modelo inicial evolucionó hacia la separación de la estructura cónica de la cubierta respecto del terreno, mediante la interposición de una pared perimetral vertical formada por la yuxtaposición de tablas o ramajes dispuestos en vertical, sobre la que apoyaba la base de la cubierta cónica, manteniéndose la planta circular (Fig. 3).

Progresivamente, las cubiertas cónicas dejaron de finalizar en punta para hacerlo con una pequeña cumbrera horizontal (Fig. 4), aun sin perder su diseño en forma de cono. El progresivo alargamiento de esta incipiente cumbrera inicial dio lugar a la aparición de construcciones de planta ovalada, o rectangular de lados cortos curvados, asentadas directamente sobre el terreno, y rematadas por cubiertas a dos aguas con cumbrera longitudinal, que los bribri denominan Órowe.

La implantación de grandes compañías frutícolas y bananeras foráneas en la zona durante las primeras décadas del siglo XX introdujo importantes influencias externas en los modos de vida tradicionales, que en el campo de la arquitectura doméstica se manifestaron en la aparición de viviendas elevadas sobre postes o pies derechos de madera, a modo de palafitos, de planta cuadrangular o rectangular, con cubiertas a cuatro aguas y plantas compuestas por varios cuerpos anejos que conforman una única residencia, a menudo como resultado de procesos de ampliación de un núcleo inicial (Fig. 5). Uno de estos cuerpos suele estar destinado exclusivamente a cocina, y es frecuente que éste conserve la cubierta vegetal tradicional y la planta circular o poligonal de seis o más lados, frente a los módulos destinados a dormitorio, que adoptaron la planta cuadrangular o rectangular, y sustituyen la cubierta tradicional vegetal de cuatro vertientes por otra de chapa de cinc a una o dos aguas. A estas viviendas se les conoce en el ámbito bribri como Tambo. 


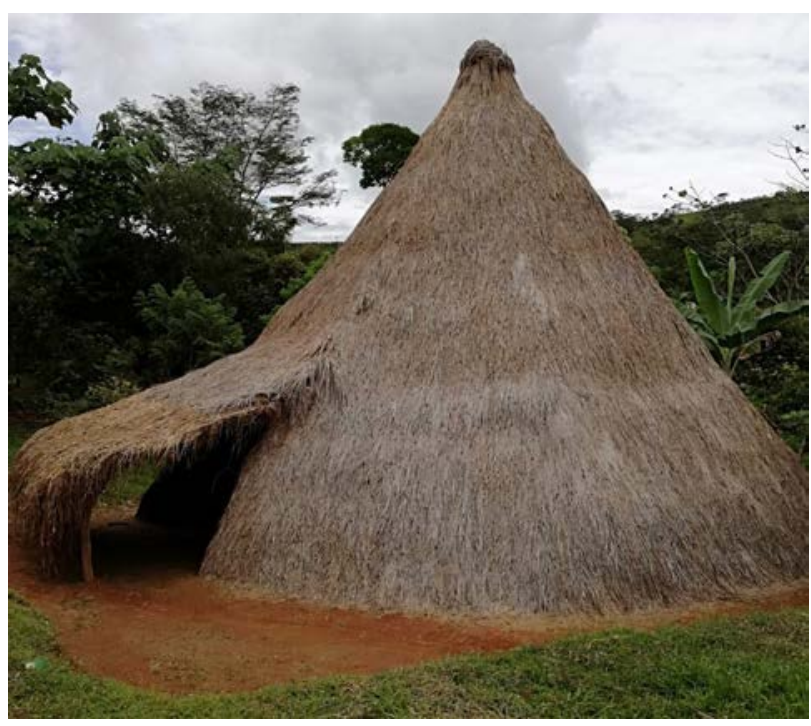

Fig. 2 Casa Cósmica Bribri en Cabagra (Costa Rica)

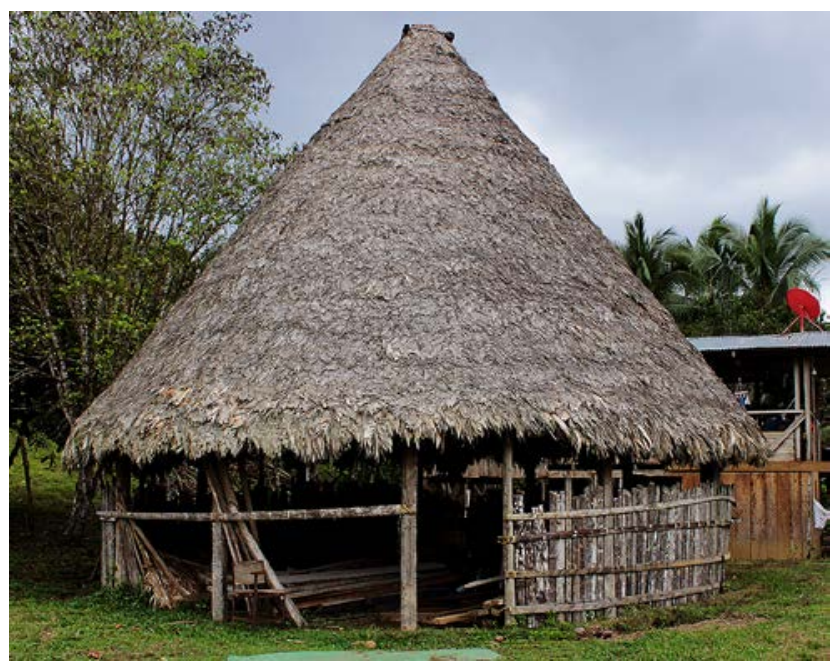

Fig. 4 Escuela primaria en Sieikin, territorio naso

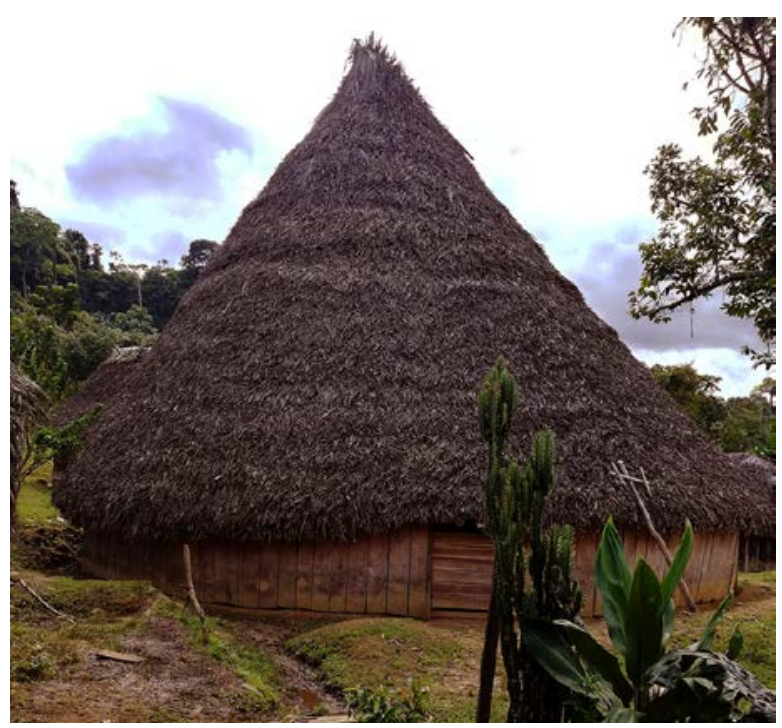

Fig. 3 Casa tradicional en Coclecito, territorio ngäbe

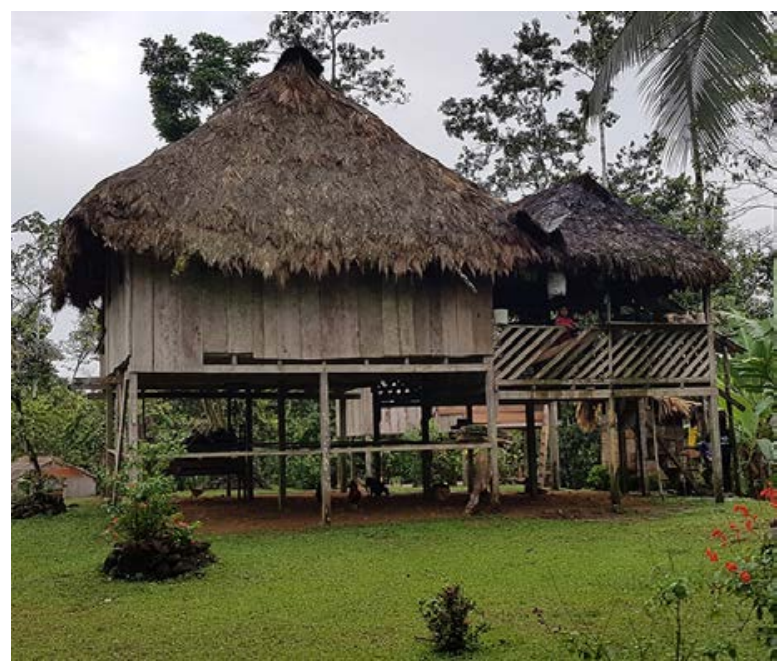

Fig. 5 Casa de tipo Tambo en Sieikin, territorio naso

\subsection{Variantes constructivas por etnias}

$\mathrm{Al}$ margen de los rasgos comunes ya expuestos, se observan algunas diferencias entre los usos constructivos de cada etnia, que se manifiestan principalmente en el diseño del cobijo de la cubierta y en la materia prima empleada para elaborarlo. En territorio naso son frecuentes las cubiertas vegetales a cuatro aguas con continuidad entre sus faldones a ambos lados de las limatesas. La estructura de cubierta se arma sobre pares, limatesas y correas de ramas de laurel, atadas con bejucos o con hilo de nylon. Los faldones de los lados largos de la cubierta suelen estar reforzados estructuralmente por medio de riostras oblicuas dispuestas en el mismo plano que el propio faldón, que previenen el plegamiento longitudinal de la estructura. El cobijo se elabora con hojas de palanquilla, que se cosen por su peciolo cuando aún están verdes a una vara delgada y rectilínea de caña brava (Gynerium sagittatum) de hasta $3 \mathrm{~m}$ de longitud, para formar las esteras, que han de secarse por completo a la sombra antes de ser puestas en obra.

En territorio bribri, las cubiertas a cuatro aguas tienen los faldones de los lados largos solapados sobre los de los lados cortos. En el extremo superior de ambos hastiales, junto a la cumbrera de los faldones cortos, se deja un espacio triangular sin cobijar para favorecer la ventilación del interior y garantizar con ello la evacuación de humos y humedades del interior. La estructura de cubierta se arma con ramas de laurel, y el cobijo se hace con hojas de suita cosidas a una vara larga para formar esteras, del mismo modo que hacen los naso. 
Tanto en territorio naso como en territorio bribri se fijan las esteras a la estructura de cubierta con bejuco o con hilo de nylon, con la vara en posición horizontal, y se solapan unas sobre otras desde abajo hacia arriba, para evitar las filtraciones de agua de lluvia durante la fase de escorrentía. El humo de la cocina contribuye a impermeabilizar los cobijos y a hacerlos más resistente frente a la putrefacción y los insectos. La durabilidad de un cobijo se sitúa entre los 10 y los 30 años, y depende de cuatro factores: de la densidad de hojas de cada estera, de la densidad de esteras en el cobijo, del grado de ahumado de la materia vegetal que lo conforma, y de que las hojas hayan sido cortadas con la luna en cuatro menguante. Hasta donde sabemos, no existe un fundamento científico que explique esto último, pero entre los indígenas es una creencia muy arraigada.

En territorio ngäbe es frecuente también el solapamiento de los faldones largos de la cubierta sobre los faldones cortos, como sucede entre los bribri, aunque con peculiaridades muy marcadas, como el hecho de que uno de los dos faldones cortos desciende en su desarrollo hasta alcanzar la base del forjado, dejando ese lateral de la vivienda sin pared vertical, justamente en el flanco en el que se ubica la cocina. Los cobijos ngäbe se hacen con hoja de palma. Cada hoja se corta longitudinalmente en dos mitades por el centro de su nervio principal, y después de secadas de manera natural, se colocan las mitades contrapeadas, una con los foliolos hacia abajo, y la contigua con los foliolos hacia arriba.

En el territorio buglé, situado en un entorno de sabana de montaña, el medio físico impone condiciones ambientales sustancialmente distintas a las del bosque tropical, lo que se traduce en diferencias muy significativas en cuanto al diseño de los edificios y a los materiales empleados para su construcción. Como mecanismo de defensa contra los fuertes vientos, las viviendas no están conformadas por un único cuerpo de dos alturas, sino por varios edificios pequeños de una sola altura, exentos pero muy próximos entre sí, agrupados en el interior del predio familiar, que suele estar cercado en todo su perímetro. Cada uno de estos edificios consta normalmente de un único espacio habitable con una función propia bien definida. En cada conjunto familiar alternan los edificios de planta circular y cubierta vegetal cónica, con los de planta rectangular, muchos de ellos ya cubiertos con chapa de cinc ondulada. El nivel de uso del interior de la vivienda lo constituye la superficie del propio terreno, solución que viene favorecida por los bajos índices de humedad capilar. La pared vertical perimetral de la base del edificio se construye con barro aplicado en fresco sobre un armazón fabricado con ramas trenzadas, con lo que se consigue aislar el espacio interior con respecto al viento y al descenso de las temperaturas nocturnas, en un entorno de escasa humedad ambiental.

En los edificios de planta circular, la cubierta cónica apoya sobre cuatro pies derechos verticales que quedan exentos en el interior del espacio habitable. Los de planta cuadrangular o rectangular rematan con cubiertas de pabellón a cuatro aguas. La estructura de cubierta se hace con un entramado ligero de ramas y varas ante la ausencia de especies vegetales de mayor porte en el entorno. Los cobijos se hacen con la denominada paja hueso. La vivienda buglé resulta de la adaptación de las tradiciones culturales indígenas a un entorno de sabana en zona de montaña.

\section{Conclusión}

El proyecto de investigación al que hacen referencia estas páginas pretende promover el conocimiento de la arquitectura tradicional de las comunidades indígenas de Panamá como primer paso imprescindible para la posterior protección activa de dicho patrimonio y para la programación futura de acciones orientadas a garantizar su conservación, difusión y puesta al servicio de la sociedad. También se pretende sensibilizar a las propias comunidades acerca del valor de su arquitectura vernácula como elemento destacado del patrimonio cultural panameño, y mostrarles los valores cultural, social e identitario de los edificios construidos con técnicas tradicionales. Esta sensibilización será, sin duda, la más eficaz herramienta para garantizar la conservación de ese patrimonio para las generaciones futuras.

Los edificios estudiados tienen un indudable valor como patrimonio vernáculo, pero son perecederos a corto plazo: por un lado, por su naturaleza vegetal en un entorno tropical, que los hace muy vulnerables a la acción de la humedad y los xilófagos; y por otro, porque las propias familias manifiestan un alto grado de movilidad en entornos reducidos, y con frecuencia desmontan sus viviendas para montarlas en una nueva ubicación. Ninguno de los edificios estudiados hasta el momento tiene más de 30 años de antigüedad, y muchos de ellos han sido levantados en la última década, pese a lo cual muestran un aspecto ancestral. 
Estas circunstancias nos mueven a reflexión acerca de la protección de este tipo de patrimonio. En tales condiciones no es posible proteger los edificios en sí mismos. Debemos intentar proteger el patrimonio inmaterial que los genera, es decir, el conocimiento ancestral, y el empleo de los materiales, las técnicas constructivas y la morfotipología tradicionales. Los propios indígenas se muestran muy preocupados por el riesgo de que este saber de transmisión oral se pierda. Debemos trabajar por la conservación de los mecanismos de transmisión de ese saber.

\section{Referencias}

Davis, E. (2010). Diagnóstico de la Población Indígena de Panamá con base en los Censos de Población y Vivienda de 2010. Panamá: Contraloría General de la República, Instituto Nacional de Estadística y Censo.

Díaz, M. Á. (2018). Arquitectura y cambio climático. Madrid: Arquia Foundation.

González, A., y González, F. (1989). La Casa Cósmica Talamanqueña y sus simbolismos. San José de Costa Rica: Editorial de la University of Costa Rica.

Guevara, M. (s/d). Mitología y Cosmovisión en Talamanca: una interpretación dialéctica de la tradición oral indígena. Documento inédito. Mecanografiado.

Hervás, M. Á. (2018). Las estructuras funerarias de El Caño (Coclé, Panamá) entre los siglos VIII y X. Proceso constructivo y transformaciones postdeposicionales. En Actas del 56 Congreso Internacional de Americanistas (Salamanca, 16-20 julio 2018), vol. 2 (pp. 112-127).

Marín, G. (2004). La población de Bocas del Toro y la Comarca Ngöbe-Buglé hasta inicios del siglo XIX. Anuario de Estudios Centroamericanos, 30 (1-2), 119-162.

Ocampo, R. (1994). Estudio etnobotánico de las palmas empleadas por los indígenas en Talamanca, Costa Rica. Revista Forestal Centroamericana, 7, Año 3, 16-21.

Quintero, B. (2017). La casa Ngäbe y Buglé. Ni Tä Nüne Ju Kwatibe Te. Vivimos en la misma casa. Tesis de Maestría en Antropología Social. Ciudad de Panamá Universidad de Panamá. 